\title{
Bismuth vanadate: A versatile heterogeneous catalyst for photocatalytic functionalization of $\mathrm{C}\left(\mathrm{sp}^{2}\right)-\mathrm{H}$ bonds
}

Fan-Lin Zeng

Zhengzhou University

Hu-lin Zhu

Zhengzhou University

Ru-Nan Wang

Zhengzhou University

Xiao-Ya Yuan

Zhengzhou University

Kai Sun

Zhengzhou University

Lingbo Qu

Green Catalysis Center, College of Chemistry, Zhengzhou University

Xiao-Lan Chen

Zhengzhou University

Bing Yu ( $\sim$ bingyu@zzu.edu.cn )

Zhengzhou University

\section{Article}

Keywords: BiVO4, C(sp2)-H functionalization reactions, photocatalyst

Posted Date: October 29th, 2021

DOI: https://doi.org/10.21203/rs.3.rs-1020160/v1

License: (9) This work is licensed under a Creative Commons Attribution 4.0 International License. Read Full License 


\section{Abstract}

Bismuth vanadate (BiV04) could be prepared by the hydrothermal kettle method. Herein, the synthesized BiV04-180 is demonstrated to be a versatile and stable heterogeneous photocatalyst for a series of $\mathrm{C}(\mathrm{sp} 2)-\mathrm{H}$ functionalization reactions under visible light irradiation at ambient conditions. A series of functionalized compounds such as tetrahydroquinolines, 3-arylmethyl indoles, a-aryl a-amino acid esters, and sulfurized/selenized/thiocyanated heterocycles were successfully synthesized in good yields (>70 examples, including modification of drugs and peptides). The BiVO4 photocatalyst has the advantages of being recyclable, low-cost, air-tolerant, and high efficiency, which is the typical characteristic of overcoming the shortcomings of homogeneous catalysts.

\section{Introduction}

The application of renewable and clean visible light to achieve various organic transformations is the dream of synthetic chemists for nearly a century. ${ }^{1-3}$ Moreover, the harvest of visible light for organic reactions could avoid environmental issues and carbon dioxide production in the traditional thermochemical process. ${ }^{4,5}$ In the past decade, the important contributions of chemists in organic photochemical synthesis have also led to the revival of photochemistry. ${ }^{6-9}$ In typical photocatalytic reactions, the discovery of efficient and robust photocatalysts, such as transition metal complexes and organic dyes, is extremely essential. ${ }^{10-14}$ For example, for the photocatalytic functionalization of $\mathrm{C}-\mathrm{H}$ bonds, ${ }^{15-22}$ Hong's group employed $\mathrm{Pd}\left(\mathrm{PPh}_{3}\right)_{4}$ as a photocatalyst to achieve direct $\mathrm{C}\left(\mathrm{sp}^{2}\right)-\mathrm{H}$ alkylation reactions. ${ }^{23-27}$ Additionally, Lei's group used $\mathrm{Acr}^{+}-\mathrm{Mes} \cdot \mathrm{ClO}_{4}{ }^{-}$as an organic photocatalyst to realize the visible-light-induced amination of $\mathrm{C}\left(\mathrm{sp}^{2}\right)-\mathrm{H}$ of arenes. ${ }^{28}$ Nonetheless, the transition metal complexes (ruthenium, iridium, etc) are expensive and non-renewable, while the organic dyes suffer from photobleaching during the reaction, which still limits their application. ${ }^{29-31}$ Moreover, these homogeneous photocatalysts are difficult to recycle and reuse after the reactions. Therefore, from the perspective of sustainable chemistry, it is highly desirable to explore inexpensive, stable, and recyclable catalysts for various photocatalytic organic transformations.

In the past decades, semiconductor materials, particularly $\mathrm{TiO}_{2}$, have been extensively applied in the fields of solar energy harvest due to their excellent photovoltaic performance and good stability. ${ }^{32-37}$ Recently, the application of durable semiconductors for visible-light-induced organic reactions has attracted great interest from organic chemists. ${ }^{38-47}$ For example, Cong's group reported selective aerobic oxidation of benzyl ethers by eosin Y-sensitized $\mathrm{TiO}_{2}$ as a photocatalyst in 2017.48 In 2018, Rueping et al employed graphitic carbon nitride $\left(\mathrm{g}-\mathrm{C}_{3} \mathrm{~N}_{4}\right)$ as a photocatalyst for the a-aminoalkylation heterocycles. ${ }^{49}$ In 2019 König's group realized g- $\mathrm{C}_{3} \mathrm{~N}_{4}$-photocatalyzed bifunctionalization of heteroarenes/arenes. ${ }^{50}$ Moreover, the applications of perovskites as photocatalysts for $\mathrm{C}-\mathrm{C}, \mathrm{C}-\mathrm{N}$, and $\mathrm{C}-\mathrm{O}$ bond-formations were disclosed by Yan's group. ${ }^{51-53}$ Despite these encouraging advances, semiconductor-involved heterogeneous photocatalysis for visible-light-induced organic transformations is still in its infancy. 
Therefore, the development of efficient, stable, and versatile heterogeneous photocatalysts based on semiconductors for various organic reactions remains a challenging task.

Since Kudo's group used bismuth vanadate $\left(\mathrm{BiVO}_{4}\right)$ as a photocatalyst to achieve photocatalytic water oxidation under visible light irradiation, ${ }^{54} \mathrm{BiVO}_{4}$ has become a leading-edge photocatalyst for energy conversion and environmental remediation due to its excellent performance and outstanding stability. ${ }^{55-}$ ${ }^{60}$ However, the application of $\mathrm{BiVO}_{4}$ in organic synthesis is rarely reported. ${ }^{61}$ With our ongoing studies on photocatalysis and synthetic chemistry, ${ }^{62,63}$ we herein disclose that $\mathrm{BiVO}_{4}$ is a universal and robust heterogeneous photocatalyst for the functionalization of $\mathrm{C}\left(\mathrm{sp}^{2}\right)-\mathrm{H}$ bonds to construct different types of arenes and heteroarenes under visible light irradiation at ambient conditions (Scheme 1). As a result, various products including tetrahydroquinolines, 3-arylmethyl indoles, a-aryl a-amino acid esters, and sulfurized/selenized/thiocyanated heterocycles were successfully synthesized under mild conditions.

\section{Results}

A series of $\mathrm{BiVO}_{4}$ were efficiently prepared from the solution of $\mathrm{Bi}\left(\mathrm{NO}_{3}\right)_{3} \cdot 5 \mathrm{H}_{2} \mathrm{O}$ and $\mathrm{NH}_{4} \mathrm{VO}_{3}$ via hydrothermal methods at different temperatures $\left(140,160,180^{\circ} \mathrm{C}\right)$. Then the as-prepared $\mathrm{BiVO}_{4}$ powder was annealed at $400{ }^{\circ} \mathrm{C}$ for $2 \mathrm{~h}$ in air to obtain the final $\mathrm{BiVO}_{4}$ (denoted as $\mathrm{BiVO}_{4}-\mathbf{1 4 0}, \mathrm{BiVO}_{4}-160$, and $\mathrm{BiVO}_{4}-180$ ) (Scheme 1i, see the Supporting Information for details). The synthesized $\mathrm{BiVO}_{4}$ semiconductors were further characterized by X-ray diffraction (XRD). It was found that all three crystals are monoclinic scheelite bismuth vanadate compared with the standard pattern (Fig. 1i-iv).

In addition, the morphology was studied by scanning electron microscopy (SEM). As shown in Fig. 2 the $\mathrm{BiVO}_{4}$ prepared at different temperatures showed similar elliptical rod nanoparticles shapes.

Then, we are surprised to find that the prepared $\mathrm{BiVO}_{4}$ had good absorption in the ultraviolet and visible light regions, and the band gap is calculated to be $2.4 \mathrm{eV}$ from the UV/Vis absorbance spectrum (Fig. 3i, Fig. S2). The transient photocurrent response analysis was conducted to evaluate the photoelectrochemical reversibility of these materials (Fig. 3ii). It was found that the light irradiation could induce the separation of holes and electrons to cause a sharp increase in current, which returned to the original state under dark. These results show that the three types of prepared $\mathrm{BiVO}_{4}$ semiconductors have good reversibility and optical stability. Among them, $\mathrm{BiVO}_{4}-\mathbf{1 8 0}$ gives the highest photocurrent, which implies $\mathrm{BiVO}_{4}-180$ may be an active catalyst for photocatalytic reactions.

Next, the photoluminescence $(\mathrm{PL})$ spectrum was studied to reflect the recombination process of photogenerated electron-hole pairs in semiconductor materials. As shown in Fig. 4i, the PL intensity of $\mathrm{BiVO}_{4}-180$ is lower than $\mathrm{BiVO}_{4}-160$ and $\mathrm{BiVO}_{4}-140\left(\lambda_{\mathrm{ex}}=320 \mathrm{~nm}\right)$. Generally, the weaker the emission intensity, the lower the photocarrier recombination efficiency, and the better the separation rate of electron-hole pairs. ${ }^{64,65}$ Therefore, these results suggest that the photogenerated electron-hole pairs of $\mathrm{BiVO}_{4}-\mathbf{- 1 8 0}$ are easier to separate, which will be advantageous to the photocatalytic activity. Moreover, the 
electron paramagnetic resonance (EPR) spectrum shows that the prepared $\mathrm{BiVO}_{\mathbf{4}} \mathbf{- 1 8 0}$ has a characteristic oxygen vacancies (OVs) signal after $0.5 \mathrm{~h}$ of visible light exposure, indicating that OVs have been successfully generated on the $\mathrm{BiVO}_{4}$ semiconductor (Fig. $4 \mathrm{ii}$ ). ${ }^{66}$ Based on the above-mentioned results, we envisioned that $\mathrm{BiVO}_{4}-\mathbf{1 8 0}$ could be a privileged catalyst for heterogeneous photocatalytic organic transformations.

In order to explore the photocatalytic performance of the prepared $\mathrm{BiVO}_{4}$ catalysts, we started our research on the construction of tetrahydroquinoline derivatives through visible-light-induced $\mathrm{C}-\mathrm{H}$ functionalization of $N, N$-dimethylanilines. First, $N, N$-dimethylaniline (1a) and $N$-phenylmaleimide (2a) were employed as the model substrates for the synthesis of pyrrolotetrahydroquinoline (4a). The optimization study was promoted by $\mathrm{BiVO}_{4}$ catalysts under irradiation of blue LED (details see Supporting Information, Table S1). After extensive experiments, the optimal conditions A were established as follows: $1 \mathrm{a}(0.6 \mathrm{mmol}), \mathbf{2 a}(0.2 \mathrm{mmol}), \mathrm{BiVO}_{4}-180$ (5 mol\%), 2-methyltetrahydrofuran (2Me-THF, $2 \mathrm{~mL}$ ) as a green solvent at room temperature for $3 \mathrm{~h}$ in an air atmosphere under the irradiation of $5 \mathrm{~W}$ blue LED $(460 \mathrm{~nm})$. Under the optimized conditions A, the target product $4 \mathrm{a}$ was obtained with $80 \%$ isolated yield. Subsequently, we explored the scope of the synthesized pyrrolotetrahydroquinolines (4) under optimal conditions (Table 1). Firstly, N,N-dimethylanilines 1 bearing different substituents ($\left.\mathrm{CH}_{3},-\mathrm{OCH}_{3},-\mathrm{Br}\right)$ on benzene rings were studied. When electron-donating groups $\left(-\mathrm{CH}_{3},-\mathrm{OCH}_{3}\right)$ bearing $\mathrm{N}, \mathrm{N}$-dimethylanilines were applied as substrates, the target products $(\mathbf{4 b}-\mathbf{c})$ were obtained in moderate yields. The $N, N$-dimethylaniline with an electron-withdrawing halide $(-\mathrm{Br})$ at the $p$-position rendered the desired product $\mathbf{4} \mathbf{d}$ in good yield. As can be seen, $\mathrm{N}, \mathrm{N}$-dimethylanilines with $-\mathrm{CH}_{3}$ at the $\mathrm{m}$-position gave

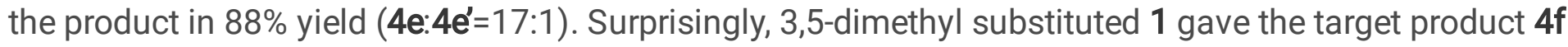
with $97 \%$ yield. Meanwhile, 1 a reacted with different maleimide 2 bearing benzyl and alkyl groups (-Bn, $\left.-\mathrm{CH}_{3},{ }^{t} \mathrm{Bu},-\mathrm{Cy}\right)$ delivered the target products $4 \mathrm{~g}$-j in $35-71 \%$ yields. When $\mathrm{N}, \mathrm{N}$-dimethylnaphthalen- $1-$ amine $1 \mathbf{k}$ was used as a substrate, the target product $\mathbf{4} \mathbf{k}$ was still obtained in a moderate yield. In addition, substituted phenylmaleimides 2 could also be converted into the corresponding products in good yield when $\mathrm{R}^{4}$ was $-\mathrm{Et}$, $-\mathrm{Br}$, and - Ac groups. Importantly, the reaction of hormone drug mifepristone and $\mathbf{2 a}$ successfully provides the target product $\mathbf{4 0}$ with $55 \%$ yield. Meanwhile, the model reaction in gram-scale generated product $4 a$ with the isolated yield of $65 \%$, indicating that the catalytic method has practical value (Scheme S2).

\section{Table 1. Synthesis of functionalized tetrahydroquinolines ${ }^{a}$}




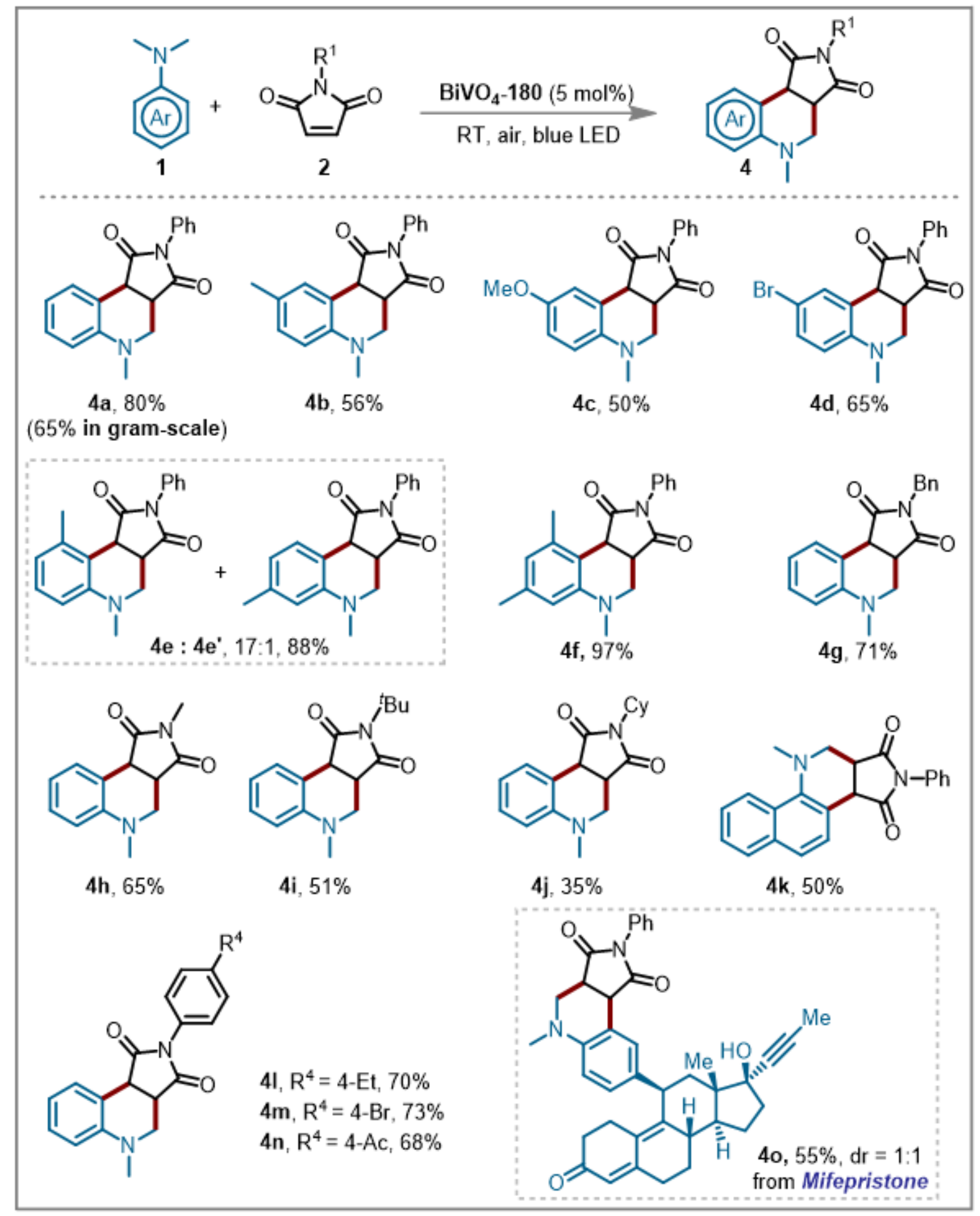

a Reaction conditions A: 1 (0.6 mmol), 2 (0.2 mmol), BiVO 4 -180 (5 mol\%), 2-Me-THF (2 mL) with the irradiation of blue LED ( $5 \mathrm{~W}$ ) under air at room temperature for 3-4 h. Isolated yields were given.

In addition to maleimide, various 1,1-dicyanostyrenes 3 could also be applied as substrates for the coupling with $N, N$-dimethylanilines catalyzed by $\mathrm{BiVO}_{4}-180$. After slight 
modification of the reaction conditions, the model reaction of $1 \mathrm{~b}$ and $3 \mathrm{a}$ in green solvent dimethyl carbonate (DMC) gave the target product 5a with a yield of 70\% (Table 2). Further scope expansion showed good applicability, yielding the desired products $5 \mathrm{~b}-\mathrm{j}$ in 45-85\% yields. Surprisingly, the hormone therapy drug ulipristal acetate was also suitable in this procedure, and the corresponding product $5 \mathbf{k}$ was obtained in a moderate yield (45\%).

\section{Table 2. Synthesis of $5^{a}$}

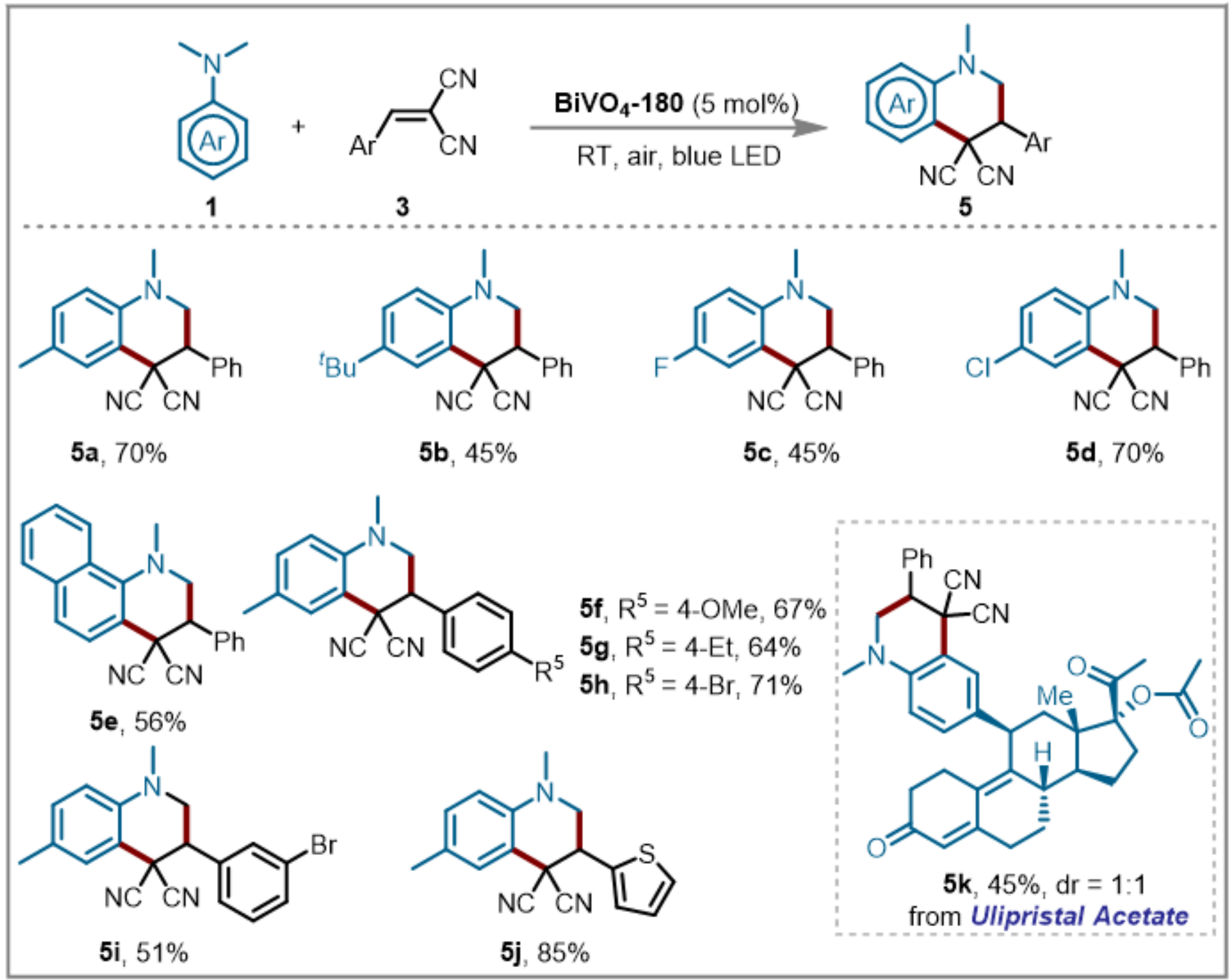

a Reaction conditions B: 1 (0.3 mmol), 3 (0.2 mmol), $\mathrm{BiVO}_{4}(5 \mathrm{~mol} \%), \mathrm{DMC}(2 \mathrm{~mL})$ with the irradiation of blue LED $(10 \mathrm{~W})$ under air at room temperature for 19-48 h. 
To explore the versatility of the catalytic activity of $\mathrm{BiVO}_{4}-180$, the 3-arylmethyl indoles 7 were constructed by the $\mathrm{C}-\mathrm{H}$ functionalization reaction of $\mathrm{N}, \mathrm{N}$-dimethylanilines 1 and indoles 6 using $\mathrm{BiVO}_{4}-180$ as a photocatalyst (Table 3). After conditions optimization (details see Supporting Information, Table S2), the scope of various substituted $\mathbf{1}$ and $\mathbf{6}$ was further investigated. The products $\mathbf{7 a - s}$ were afforded in $48-85 \%$ isolated yields under visible light irradiation.

As a component of peptides and proteins, amino acids have attracted much attention, and their modification, especially through organic synthesis, is of great significance in the field of pharmacy and biological research. ${ }^{67-70}$ By using the $\mathrm{BiVO}_{4}-180$ catalysis strategy, we also realized the modification of amino acid derivatives and peptides through semiconductor photocatalysis. Firstly, the synthesis of aromatic/heterocyclic a-amino acid esters 10 was achieved through the reaction of aromatic heterocycles 8 and $\mathrm{N}$-arylglycine esters $\mathbf{9}$ (Table 3). A range of aromatic heterocycles reacted with $\mathrm{N}$-arylglycine esters smoothly to give the desired products $10 \mathbf{a}-\mathbf{i}$ in moderate to excellent yields (45-92\%). Furthermore, more challenging transformations to construct functionalized peptides are investigated, which are usually prone to oxidative cleavage and therefore difficult to control. Surprisingly, the reaction of different substituted peptides with 2-phenylindole delivered the desired product $10 \mathrm{j}-\mathrm{o}$ in moderate yields (43-50\%).

In addition, we also investigated the $\mathrm{C}-\mathrm{H}$ functionalization of aromatic heterocycles with thioethers, selenoether, and $\mathrm{NH}_{4} \mathrm{SCN}$ (Table 3). A series of vulcanization, selenation, and thiocyanation products 12aq were obtained in moderate to excellent yields (40-95\%).

[Table 3 is available in the supplementary files section.]

In order to verify the stability and reusability of the catalytic system, we carried out the recovery experiment of $\mathrm{BiVO}_{4}-\mathbf{- 1 8 0}$ (Scheme 2). The target product 4 a was obtained in $80 \%$ yield by model reaction of $1 \mathrm{a}$ and $\mathbf{2 a}$ under the reaction conditions $\mathrm{A}$. Then the catalyst was recovered by centrifugation, washed with water and ethanol, and then dried at $80^{\circ} \mathrm{C}$. Subsequently, the recovered catalyst could be used for the next run. The results showed that the recovered catalyst still maintain excellent activity in the eighth run. In addition, powder X-ray diffraction (XRD) confirmed that the structure of the recovered catalyst $\mathrm{BiVO}_{4}-180$ did not change significantly (Fig. 1v).

To further explore the mechanism of this catalytic strategy, we conducted some control experiments (Scheme 3i). First, the two radical scavengers 2,2,6,6-tetramethylpiperidin-1-yl-oxidanyl (TEMPO) and 2,6di-tert-butyl-4-methylphenol (BHT) were added to the model reaction of $\mathbf{1} \mathbf{a}$ and $\mathbf{2} \mathbf{a}$. It was found that both reactions were completely inhibited, indicating that this transformation may be a radical process. To support this hypothesis, the reaction solution with $\mathrm{BHT}$ was analyzed by high-resolution mass spectrometry (HRMS), the signal of $\mathrm{m} / \mathrm{z} 340.2635$ indicated that the radical adduct $4 \mathbf{a}^{\prime}$ was formed by $\mathrm{BHT}$ and the in situ produced aminomethyl radical (Fig. S3). Moreover, when ammonium oxalate and 
$\mathrm{K}_{2} \mathrm{~S}_{2} \mathrm{O}_{8}$ as the scavengers for holes $\left(\mathrm{h}^{+}\right)$and electrons, respectively, were added to the template reaction, the reactions were inhibited, showing that the $\mathrm{BiVO}_{4}-\mathbf{- 1 8 0}$ semiconductor participates in the reaction. The reaction under a nitrogen atmosphere didn't occur, suggesting that the oxygen in the air should participate in the reactions.

Based on the above control experiments and previous reports, we proposed the tentative mechanism of this transformation (Scheme 3ii). First, under visible light irradiation, $\mathbf{B i V O}_{\mathbf{4}} \mathbf{- 1 8 0}$ semiconductor was excited to generate holes on the valence band (VB) and electrons on the conduction band (CB). Then, the holes on VB obtain electrons from 1a by single electron transfer (SET) to form intermediate 1aa. Subsequently, $1 \mathrm{aa}$ loosed a proton to form radical $\mathbf{1 a b}$. Then, radical $1 \mathrm{ab}$ experienced an addition reaction with $\mathbf{2} \mathbf{a}$ to form intermediate $\mathbf{4 a a}$, which was followed by an intramolecular cyclization to generate intermediate $\mathbf{4 a b}$. Finally, $\mathbf{4 a b}$ was converted into the target product $\mathbf{4 a}$ through the SET and deprotonation process. In addition, the control experiments and the plausible mechanism for the synthesis of 7 are shown in Scheme S3-4.

\section{Discussion}

In summary, a semiconductor bismuth vanadate $\left(\mathrm{BiVO}_{4}-180\right)$ was prepared and characterized by XRD, UV/Vis absorbance, photocurrent, PL spectrum, EPR, and SEM. Importantly, the $\mathbf{B i V O}_{\mathbf{4}} \mathbf{- 1 8 0}$ is demonstrated to be a promising heterogeneous photocatalyst, which has been applied in the photocatalytic $\mathrm{C}\left(\mathrm{sp}^{2}\right)-\mathrm{H}$ bonds functionalization reactions to synthesize various heterocycles including tetrahydroquinolines, 3-arylmethyl indoles, a-aryl a-amino acid esters, and sulfurized/selenized/thiocyanated heterocycles. The semiconductor catalyst with stable performance, easy preparation, and high activity has shown great potential in photocatalytic organic reactions. The application of this inexpensive and recyclable $\mathrm{BiVO}_{4}-\mathbf{1 8 0}$ as an alternative to traditional homogeneous photocatalyst (i.e., transition metal catalysts and organic dyes) for photocatalytic organic reactions is underway in our laboratory.

\section{Methods}

Synthesis of 4 . The mixture of substrates 1 ( $0.6 \mathrm{mmol}, 3$ equiv), 2 ( $0.2 \mathrm{mmol}, 1$ equiv), $\mathrm{BiVO}_{4}-180$ (5 $\mathrm{mol} \%, 3.2 \mathrm{mg})$, and 2-Me-THF $(2 \mathrm{~mL})$ were sequentially added in a $25 \mathrm{~mL}$ reaction tube. Then the reaction tube was exposed to the irradiation of $5 \mathrm{~W}$ blue LED at room temperature for $3 \mathrm{~h}$ or $4 \mathrm{~h}$ under open-air the reaction time of specified products: $4 a-n(3 \mathrm{~h}), \mathbf{4 o}(4 \mathrm{~h})$. After the reaction, the solvent was evaporated under vacuum, all the crude products were purified by thin-layer chromatography using petroleum ether $(P E)$ and ethyl acetate $(E A)$ as eluting solvent to give the desired products 4 (PE:EA, v/v = 3:1).

Synthesis of 5 . The mixture of substrates 1 ( $0.3 \mathrm{mmol}, 1.5$ equiv), 3 ( $0.2 \mathrm{mmol}, 1$ equiv), $\mathrm{BiVO}_{4}-180$ ( 5 $\mathrm{mol} \%, 3.2 \mathrm{mg}$ ), and dimethyl carbonate (DMC) $(2 \mathrm{~mL})$ were sequentially added in a $25 \mathrm{~mL}$ reaction tube. Then the reaction tube was exposed to the irradiation of $10 \mathrm{~W}$ blue LED at room temperature for 19-48 $\mathrm{h}$ 
under open-air. The reaction time of specified products: $\mathbf{5 a}$ (48 h), $5 \mathbf{b}(36 \mathrm{~h}), \mathbf{5 c - d}(19 \mathrm{~h}), \mathbf{5 e}(24 \mathrm{~h}), \mathbf{5 f}-\mathbf{g}(36$ h), $5 \mathrm{~h}(42 \mathrm{~h}), \mathbf{5 i}(40 \mathrm{~h}), \mathbf{5 j}(\mathbf{3 6} \mathrm{h})$ and $\mathbf{5 k}(\mathbf{2 4} \mathrm{h})$. After the reaction, the solvent was evaporated under vacuum, all the crude products were purified by thin-layer chromatography using PE and EA as eluting solvent to give the desired products 5 (PE:EA, v/v, 5a-j (10:1), $5 k(4: 1)$ ).

Synthesis of 7. The mixture of substrates 1 ( $0.6 \mathrm{mmol}, 3$ equiv), 3 ( $0.2 \mathrm{mmol}, 1$ equiv), $\mathrm{BiVO}_{4}-180$ (5 mol\%, $3.2 \mathrm{mg})$, and DMSO: $\mathrm{H}_{2} \mathrm{O}, \mathrm{v} / \mathrm{v}=50: 1(2 \mathrm{~mL}: 0.04 \mathrm{~mL})$ were sequentially added in a $25 \mathrm{~mL}$ reaction tube. Then the reaction tube was exposed to the irradiation of $3 \mathrm{~W}$ blue LED at room temperature for $3 \mathrm{~h}$ under open-air. After the reaction, the solvent was evaporated under vacuum, all the crude products were purified by thin-layer chromatography using PE and EA as eluting solvent to give the desired products 7 (PE:EA, v/v, 10:1).

Synthesis of 10. The mixture of substrates $8 \mathrm{a}-\mathrm{i}\left(0.2 \mathrm{mmol}, 1\right.$ equiv), $9 \mathrm{a}-\mathrm{b}\left(0.4 \mathrm{mmol}, 2\right.$ equiv), $\mathrm{BiVO}_{4}-180$ $(5 \mathrm{~mol} \%, 3.2 \mathrm{mg})$, and $\mathrm{MeCN}(2 \mathrm{~mL})$ were sequentially added in a $25 \mathrm{~mL}$ reaction tube. Then the reaction tube was exposed to the irradiation of $10 \mathrm{~W}$ blue LED at room temperature for $24 \mathrm{~h}$ under open-air. After the reaction, the solvent was evaporated under vacuum, all the crude products were purified by thin-layer chromatography using PE and EA as eluting solvent to give the desired products 10a-i (PE:EA, v/v, 9:1). And the mixture of substrates $8 \mathrm{~b}(0.2 \mathrm{mmol}, 1$ equiv), peptides ( $0.4 \mathrm{mmol}, 2$ equiv) (peptides were synthesized following reported procedures $\left.{ }^{21}\right), \mathrm{BiVO}_{4}-180(5 \mathrm{~mol} \%, 3.2 \mathrm{mg})$, and $\mathrm{MeCN}(2 \mathrm{~mL})$ were sequentially added in a $25 \mathrm{~mL}$ reaction tube. Then the reaction tube was exposed to the irradiation of 10 $\mathrm{W}$ blue LED at $55^{\circ} \mathrm{C}$ for $72 \mathrm{~h}$ under open-air. After the reaction, the solvent was evaporated under vacuum, all the crude products were purified by thin-layer chromatography using PE and EA as eluting solvent to give the desired products 10j-o (PE:EA, v/v, 5:1).

Synthesis of 12. The mixture of substrates 8 ( $0.2 \mathrm{mmol}, 1$ equiv), 11 or $\mathrm{NH}_{4} \mathrm{SCN}(0.4 \mathrm{mmol}, 1$ equiv), BiVO $_{4}-180(5 \mathrm{~mol} \%, 3.2 \mathrm{mg})$, and $\mathrm{MeCN}(2 \mathrm{~mL})$ were sequentially added in a $25 \mathrm{~mL}$ reaction tube. Then the reaction tube was exposed to the irradiation of $10 \mathrm{~W}$ blue LED at room temperature for $5-24 \mathrm{~h}$ under open-air (the reaction time of specified products: 12a, 12b and 12g (15 h), 12c-f (18 h), 12h (22 h), 12i (5 h) and $12 \mathrm{j}-\mathbf{q}(24 \mathrm{~h})$. After the reaction, the solvent was evaporated under vacuum, all the crude products were purified by thin-layer chromatography using PE and EA as eluting solvent to give the desired products 12 (PE:EA, v/v, 100:1-10:1).

\section{Declarations}

\section{Data availability}

The authors declare that the data supporting the findings of this study are available within the article and Supplementary Information file.

\section{Acknowledgements}


We acknowledge the Center of Advanced Analysis \& Computational Science (Zhengzhou University) and the financial support from the National Natural Science Foundation of China $(21971224,22071222$, 22171249), the Key Research Projects of Universities in Henan Province (20A150006, 21A150053), the Natural Science Foundation of Henan Province (202300410375).

\section{Author contributions}

F.-L.Z. conceived the original idea and led the project. H.-L.Z., R.-N.W., and X.-Y.Y. participated in the synthesis and characterization of some compounds. F.-L.Z., K.S. and B.Y. discussed the experimental results and commented on the manuscript. B.Y., X.-L.C. and L.-B.Q. conducted general guidance, project directing.

Competing interests.

The authors declare no competing interests.

Additional information

Supplementary information. The online version contains supplementary material available at: XXXXXXX.

\section{References}

1. Xuan, J. \& Xiao, W.-J. Visible-Light Photoredox Catalysis. Angew. Chem. Int. Ed. 51, 6828-6838 (2012).

2. Zhang, Z. et al. Visible-Light-Driven Catalytic Reductive Carboxylation with CO2. ACS Catal. 10, 10871-10885 (2020).

3. Song, L. et al. Visible-Light Photoredox-Catalyzed Remote Difunctionalizing Carboxylation of Unactivated Alkenes with C02. Angew. Chem. Int. Ed. 59, 21121-21128 (2020).

4. Han, G., Liu, X., Cao, Z. \& Sun, Y. Photocatalytic Pinacol C-C Coupling and Jet Fuel Precursor Production on ZnIn2S4 Nanosheets. ACS Catal. 10, 9346-9355 (2020).

5. Yuan, T., Zheng, M., Antonietti, M. \& Wang, X. Ceramic boron carbonitrides for unlocking organic halides with visible light. Chem. Sci. 12, 6323-6332 (2021).

6. Noble, A., Mega, R. S., Pflästerer, D., Myers, E. L. \& Aggarwal, V. K. Visible-Light-Mediated Decarboxylative Radical Additions to Vinyl Boronic Esters: Rapid Access to Y-Amino Boronic Esters. Angew. Chem. Int. Ed. 57, 2155-2159 (2018).

7. Li, M., Xue, X.-S. \& Cheng, J.-P. Establishing Cation and Radical Donor Ability Scales of Electrophilic F, CF3, and SCF3 Transfer Reagents. Acc. Chem. Res. 53, 182-197 (2020).

8. Wang, P.-Z. et al. Asymmetric three-component olefin dicarbofunctionalization enabled by photoredox and copper dual catalysis. Nat. Commun. 12, 1815 (2021).

9. Shen, Y., Dai, Z.-Y., Zhang, C. \& Wang, P.-S. Palladium-Catalyzed Allylic Alkylation via Photocatalytic Nucleophile Generation. ACS Catal. 11, 6757-6762 (2021). 
10. Chen, Y., Lu, L.-Q., Yu, D.-G., Zhu, C.-J. \& Xiao, W.-J. Visible light-driven organic photochemical synthesis in China. Sci. China Chem. 62, 24-57 (2019).

11. Yu, X.-Y., Chen, J.-R. \& Xiao, W.-J. Visible Light-Driven Radical-Mediated C-C Bond Cleavage/Functionalization in Organic Synthesis. Chem. Rev. 121, 506-561 (2021).

12. Gan, Z. et al. Visible-light-promoted oxidative desulphurisation: a strategy for the preparation of unsymmetrical ureas from isothiocyanates and amines using molecular oxygen. Green Chem. 22, 2956-2962 (2020).

13. Mandal, T., Das, S. \& Det־Sarkar, S. Nickel(II) Tetraphenylporphyrin as an Efficient Photocatalyst Featuring Visible Light Promoted Dual Redox Activities. Adv. Synth. Catal. 361, 3200-3209 (2019).

14. Ding, X., Dong, C.-L., Guan, Z. \& He, Y.-H. Visible-Light-Promoted Alkylation of Indoles with Tertiary Amines by the Oxidation of a sp3 C-H Bond. Adv. Synth. Catal. 360, 762-767 (2018).

15. Hu, X.-Q., Chen, J.-R. \& Xiao, W.-J. Controllable Remote C-H Bond Functionalization by Visible-Light Photocatalysis. Angew. Chem. Int. Ed. 56, 1960-1962 (2017).

16. Kang, B. \& Hong, S. H. Photoredox mediated nickel catalyzed C(sp3)-H thiocarbonylation of ethers. Chem. Sci. 8, 6613-6618 (2017).

17. Lee, G. S., Won, J., Choi, S., Baik, M.-H. \& Hong, S. H. Synergistic Activation of Amides and Hydrocarbons for Direct C(sp3)-H Acylation Enabled by Metallaphotoredox Catalysis. Angew. Chem. Int. Ed. 59, 16933-16942 (2020).

18. Ghosh, I., Marzo, L., Das, A., Shaikh, R. \& König, B. Visible Light Mediated Photoredox Catalytic Arylation Reactions. Acc. Chem. Res. 49, 1566-1577 (2016).

19. Wang, C.-S., Dixneuf, P. H. \& Soulé, J.-F. Photoredox Catalysis for Building C-C Bonds from C(sp2)-H Bonds. Chem. Rev. 118, 7532-7585 (2018).

20. Zhang, W. et al. Direct C-H difluoromethylation of heterocycles via organic photoredox catalysis. Nat. Commun. 11, 638 (2020).

21. Firoozi, S., Hosseini-Sarvari, M. \& Koohgard, M. Solvent-free and room temperature visible lightinduced $\mathrm{C}-\mathrm{H}$ activation: $\mathrm{CdS}$ as a highly efficient photo-induced reusable nano-catalyst for the $\mathrm{C}-\mathrm{H}$ functionalization cyclization of t-amines and C-C double and triple bonds. Green Chem. 20, 55405549 (2018).

22. Hwang, J. Y., Ji, A. Y., Lee, S. H. \& Kang, E. J. Redox-Selective Iron Catalysis for alpha-Amino C-H Bond Functionalization via Aerobic Oxidation. Org. Lett. 22, 16-21 (2020).

23. Kim, D., Lee, G. S., Kim, D. \& Hong, S. H. Direct C(sp2)-H alkylation of unactivated arenes enabled by photoinduced Pd catalysis. Nat. Commun. 11, 5266 (2020).

24. Hsu, C.-W. \& Sundén, H. a-Aminoalkyl Radical Addition to Maleimides via Electron Donor-Acceptor Complexes. Org. Lett. 20, 2051-2054 (2018).

25. Zhu, S. et al. Oxygen Switch in Visible-Light Photoredox Catalysis: Radical Additions and Cyclizations and Unexpected C-C-Bond Cleavage Reactions. J. Am. Chem. Soc. 135, 1823-1829 (2013). 
26. Nicholls, T. P., Constable, G. E., Robertson, J. C., Gardiner, M. G. \& Bissember, A. C. Brønsted Acid Cocatalysis in Copper(I)-Photocatalyzed a-Amino C-H Bond Functionalization. ACS Catal. 6, 451457 (2015).

27. Yang, X.-L. et al. Oxidative Cyclization Synthesis of Tetrahydroquinolines and Reductive Hydrogenation of Maleimides under Redox-Neutral Conditions. Org. Lett. 20, 2916-2920 (2018).

28. Niu, L. et al. Photo-induced oxidant-free oxidative $\mathrm{C}-\mathrm{H} / \mathrm{N}-\mathrm{H}$ cross-coupling between arenes and azoles. Nat. Commun. 8, 14226 (2017).

29. Romero, N. A., Margrey, K. A., Tay, N. E. \& Nicewicz, D. A. Site-selective arene C-H amination via photoredox catalysis. Science 349, 1326 (2015).

30. Romero, N. A. \& Nicewicz, D. A. Organic Photoredox Catalysis. Chem. Rev. 116, 10075-10166 (2016).

31. McManus, J. B. \& Nicewicz, D. A. Direct C-H Cyanation of Arenes via Organic Photoredox Catalysis. J. Am. Chem. Soc. 139, 2880-2883 (2017).

32. Wang, L. et al. Graphitic Carbon Nitride-Based Photocatalytic Materials: Preparation Strategy and Application. ACS Sustainable Chem. Eng. 8, 16048-16085 (2020).

33. Savateev, A., Ghosh, I., König, B. \& Antonietti, M. Photoredox Catalytic Organic Transformations using Heterogeneous Carbon Nitrides. Angew. Chem. Int. Ed. 57, 15936-15947 (2018).

34. Lakhi, K. S. et al. Mesoporous carbon nitrides: synthesis, functionalization, and applications. Chem. Soc. Rev. 46, 72-101 (2017).

35. Yuan, Y. et al. Stereoselective C-C Oxidative Coupling Reactions Photocatalyzed by Zwitterionic Ligand Capped CsPbBr3 Perovskite Quantum Dots. Angew. Chem. Int. Ed. 59, 22563-22569 (2020).

36. Manley, D. W. \& Walton, J. C. Preparative semiconductor photoredox catalysis: An emerging theme in organic synthesis. Beilstein J. Org. Chem. 11, 1570-1582 (2015).

37. Miyabe, H. \& Kohtani, S. Photocatalytic single electron transfer reactions on TiO2 semiconductor. Sci. China Chem. 62, 1439-1449 (2019).

38. Ou, W., Xu, Y., Zhou, H. \& Su, C. Harnessing Photoexcited Redox Centers of Semiconductor Photocatalysts for Advanced Synthetic Chemistry. Solar RRL 5, 2000444 (2020).

39. Lin, Y. et al. Photoredox Organic Synthesis Employing Heterogeneous Photocatalysts with Emphasis on Halide Perovskite. Chem. Eur. J. 26, 13118-13136 (2020).

40. Gisbertz, S. \& Pieber, B. Heterogeneous Photocatalysis in Organic Synthesis. ChemPhotoChem 4, 456-475 (2020).

41. Li, X.-B. et al. Semiconductor nanocrystals for small molecule activation via artificial photosynthesis. Chem. Soc. Rev. 49, 9028-9056 (2020).

42. Das, S. et al. Photocatalytic (Het)arylation of C(sp3)-H Bonds with Carbon Nitride. ACS Catal., 15931603 (2021).

43. de Almeida Ribeiro, R. S. et al. Graphitic Carbon Nitride-Based Materials as Catalysts for the Upgrading of Lignocellulosic Biomass-Derived Molecules. ChemSusChem 13, 3992- 4004 (2020). 
44. Geng, P. et al. A g-C3N4-based heterogeneous photocatalyst for visible light mediated aerobic benzylic C-H oxygenations. Green Chem. 21, 6116-6122 (2019).

45. Wang, J., Ni, B., Niu, T. \& Ji, F. C3N4-Photocatalyzed aerobic oxidative cleavage of Cînc Conds in alkynes with diazonium salts leading to two different aldehydes or esters in one pot. Catal. Sci. Technol. 10, 8458-8464 (2020).

46. Martin, J. S. et al. A Nanocrystal Catalyst Incorporating a Surface Bound Transition Metal to Induce Photocatalytic Sequential Electron Transfer Events. J. Am. Chem. Soc. 143, 11361-11369 (2021).

47. Zeng, F.-L., Zhu, H.-L., Chen, X.-L., Qu, L.-B. \& Yu, B. Visible light-induced recyclable g-C3N4 catalyzed thiocyanation of C(sp2)-H bonds in sustainable solvents. Green Chem. 23, 3677-3682 (2021).

48. Ren, L., Yang, M.-M., Tung, C.-H., Wu, L.-Z. \& Cong, H. Visible-Light Photocatalysis Employing DyeSensitized Semiconductor: Selective Aerobic Oxidation of Benzyl Ethers. ACS Catal. 7, 8134-8138 (2017).

49. Cai, Y. et al. Heterogeneous Visible-Light Photoredox Catalysis with Graphitic Carbon Nitride for aAminoalkyl Radical Additions, Allylations, and Heteroarylations. ACS Catal. 8, 9471-9476 (2018).

50. Ghosh, I. et al. Organic semiconductor photocatalyst can bifunctionalize arenes and heteroarenes. Science 365, 360 (2019).

51. Zhu, X. et al. Lead halide perovskites for photocatalytic organic synthesis. Nat. Commun. 10, 2843 (2019).

52. Zhu, X., Lin, Y., Sun, Y., Beard, M. C. \& Yan, Y. Lead-Halide Perovskites for Photocatalytic a-Alkylation of Aldehydes. J. Am. Chem. Soc. 141, 733-738 (2019).

53. Han, C. et al. Recent Progress in Engineering Metal Halide Perovskites for Efficient Visible-LightDriven Photocatalysis. ChemSusChem 13, 4005-4025 (2020).

54. Kudo, A., Omori, K. \& Kato, H. A Novel Aqueous Process for Preparation of Crystal Form-Controlled and Highly Crystalline BiVO4 Powder from Layered Vanadates at Room Temperature and Its Photocatalytic and Photophysical Properties. J. Am. Chem. Soc. 121, 11459-11467 (1999).

55. Samanta, S., Khilari, S., Pradhan, D. \& Srivastava, R. An Efficient, Visible Light Driven, Selective Oxidation of Aromatic Alcohols and Amines with 02 Using BiVO4/g-C3N4 Nanocomposite: A Systematic and Comprehensive Study toward the Development of a Photocatalytic Process. ACS Sustainable Chem. Eng. 5, 2562-2577 (2017).

56. Chen, S. et al. Facet-Engineered Surface and Interface Design of Monoclinic Scheelite Bismuth Vanadate for Enhanced Photocatalytic Performance. ACS Catal. 10, 1024-1059 (2020).

57. Wang, S., Chen, P., Yun, J.-H., Hu, Y. \& Wang, L. An Electrochemically Treated BiVO4 Photoanode for Efficient Photoelectrochemical Water Splitting. Angew. Chem. Int. Ed. 56, 8500-8504 (2017).

58. Wang, S., Wang, L. \& Huang, W. Bismuth-based photocatalysts for solar energy conversion. J. Mater. Chem. A 8, 24307-24352 (2020).

59. Xiong, J., Song, P., Di, J. \& Li, H. Bismuth-rich bismuth oxyhalides: a new opportunity to trigger highefficiency photocatalysis. J. Mater. Chem. A 8, 21434-21454 (2020). 
60. Gao, R.-T. \& Wang, L. Stable Cocatalyst-Free BiVO4 Photoanodes with Passivated Surface States for Photocorrosion Inhibition. Angew. Chem. Int. Ed. 59, 23094-23099 (2020).

61. Han, S. S. et al. Facile Synthesis of BiVO4 for Visible-Light-Induced C-C Bond Cleavage of Alkenes to Generate Carbonyls. ChemSusChem 12, 3018-3022 (2019).

62. Sun, K., Lv, Q.-Y., Chen, X.-L., Qu, L.-B. \& Yu, B. Recent advances in visible-light-mediated organic transformations in water. Green Chem. 23, 232-248 (2021).

63. Liu, Y. et al. 4CzIPN-tBu-Catalyzed Proton-Coupled Electron Transfer for Photosynthesis of Phosphorylated N-Heteroaromatics. J. Am. Chem. Soc. 143, 964-972 (2021).

64. Hu, L., Hu, H., Lu, W., Lu, Y. \& Wang, S. Novel composite BiFeO3/ZrO2 and its high photocatalytic performance under white LED visible-light irradiation. Mater. Res. Bull. 120 (2019).

65. Chachvalvutikul, A. et al. Enhanced photocatalytic degradation of methylene blue by a direct Zscheme Bi2S3/ZnIn2S4 photocatalyst. Mater. Res. Bull. 111, 53-60 (2019).

66. Tan, H. L., Amal, R. \& Ng, Y. H. Alternative strategies in improving the photocatalytic and photoelectrochemical activities of visible light-driven BiVO4: a review. J. Mater. Chem. A 5, 1649816521 (2017).

67. King, T. A., Mandrup Kandemir, J., Walsh, S. J. \& Spring, D. R. Photocatalytic methods for amino acid modification. Chem. Soc. Rev. 50, 39-57 (2021).

68. Wang, C. et al. Visible-Light-Driven, Copper-Catalyzed Decarboxylative C(sp(3))-H Alkylation of Glycine and Peptides. Angew. Chem. Int. Ed. 57, 15841-15846 (2018).

69. Wang, C. et al. Visible-Light-Promoted C(sp(3))-H Alkylation by Intermolecular Charge Transfer: Preparation of Unnatural alpha-Amino Acids and Late-Stage Modification of Peptides. Angew. Chem. Int. Ed. 59, 7461-7466 (2020).

70. San Segundo, M., Guerrero, I. \& Correa, A. Co-Catalyzed C(sp3)-H Oxidative Coupling of Glycine and Peptide Derivatives. Org. Lett. 19, 5288-5291 (2017).

\section{Schemes And Tables}

Schemes 1-3 and Table 3 are available in the supplementary files section.

\section{Figures}




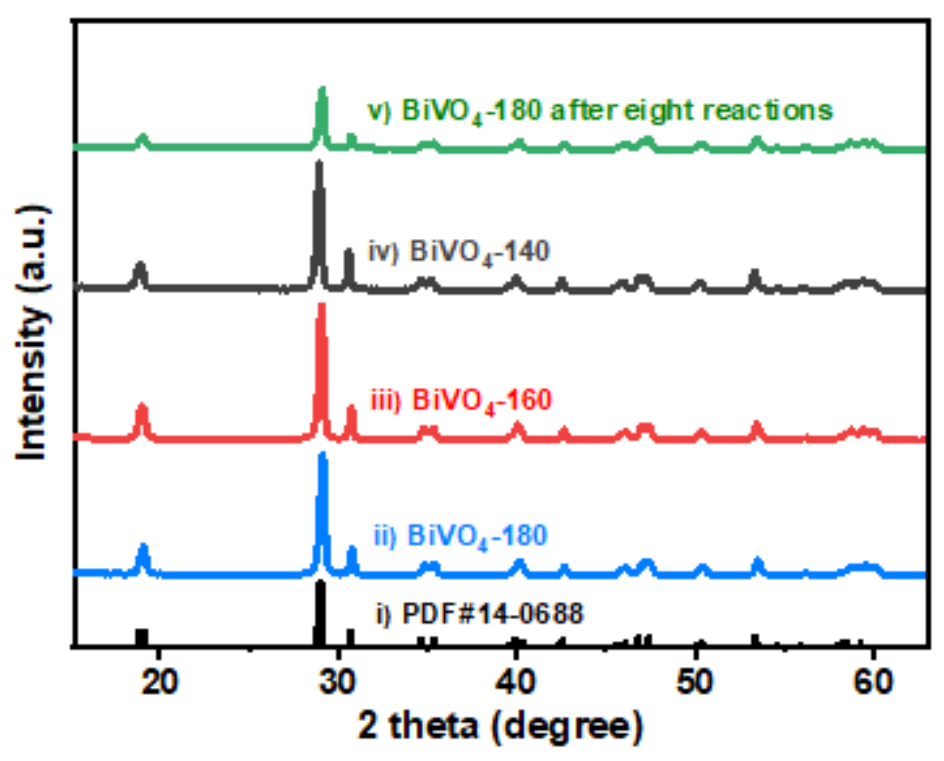

Figure 1

XRD pattern of the prepared and recycled BiVO4.
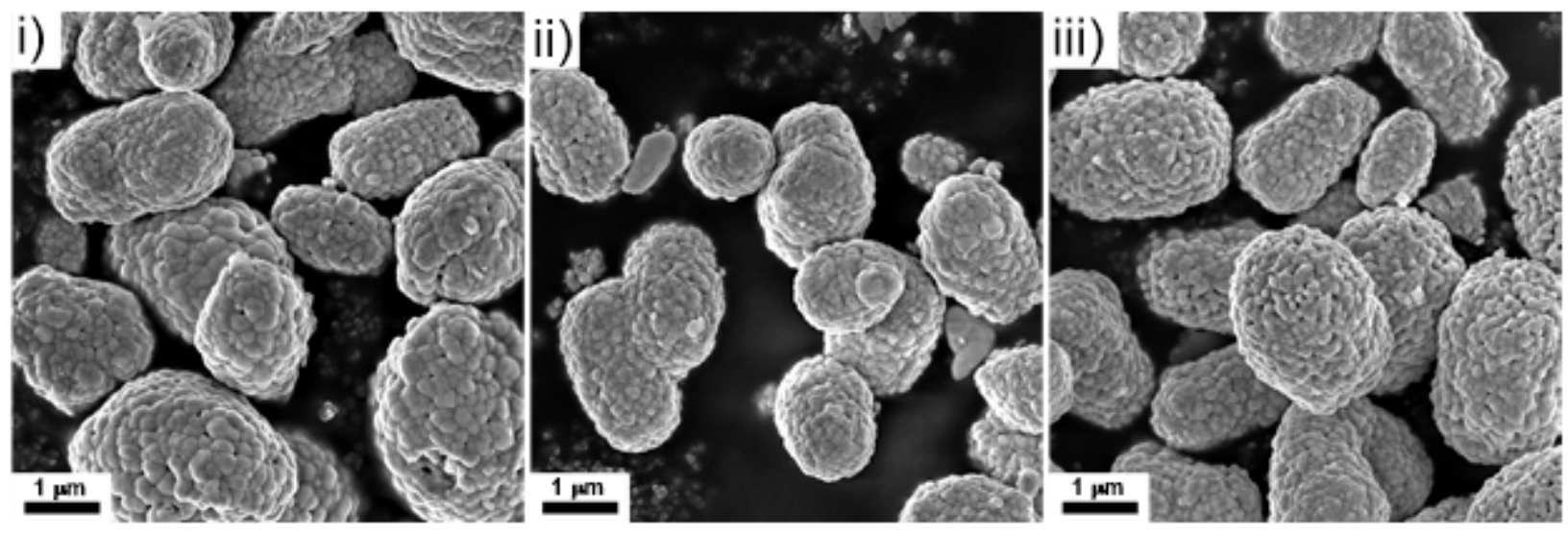

Figure 2

SEM images of i) BiV04-140, ii) BiV04-160, iii) BiV04-180. 

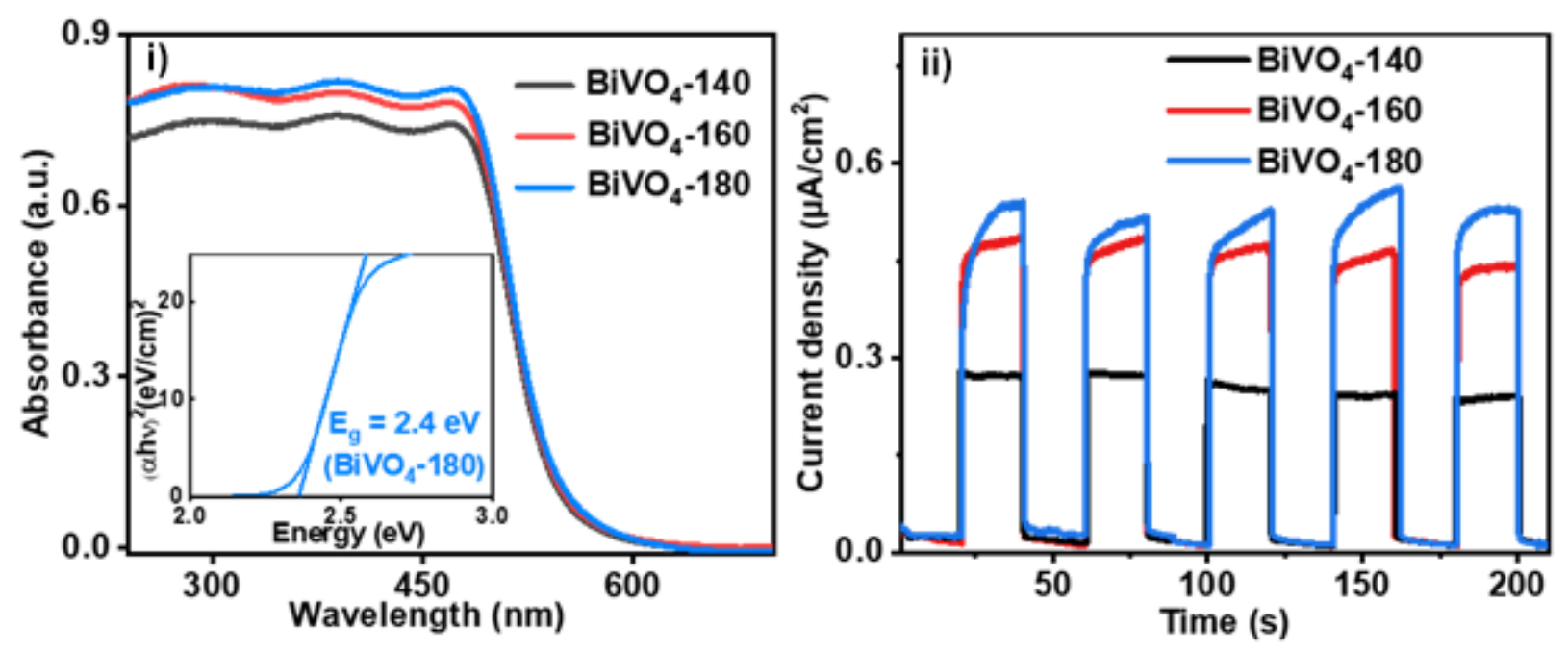

Figure 3

i) UV/Vis absorption spectrum and the corresponding Tauc plot (inset) of prepared BiVO4. ii) The transient photocurrent response analysis diagram.
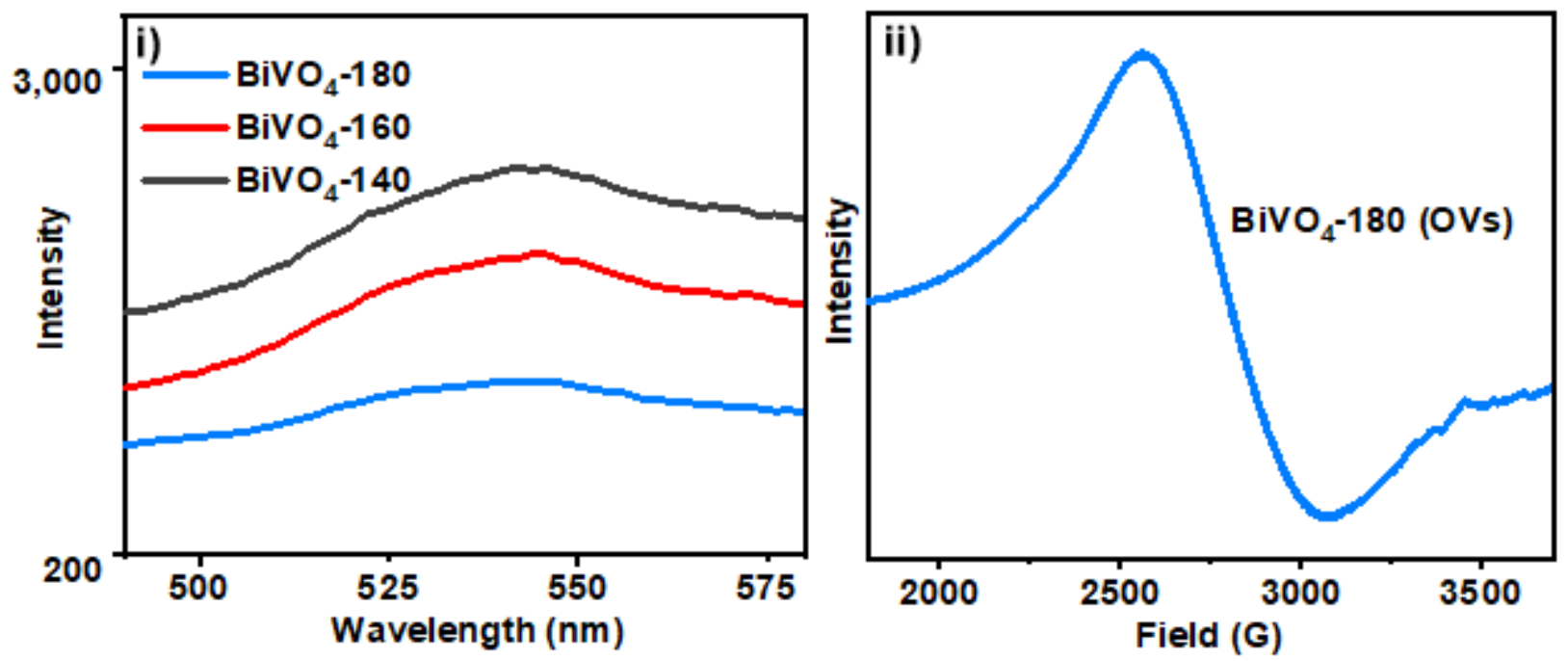

Figure 4

i) The PL spectrum of prepared BiV04, ii) The EPR spectrum of prepared BiVO4.

\section{Supplementary Files}

This is a list of supplementary files associated with this preprint. Click to download.

- Table3.docx

- Schemes.docx 
- 20211026BiVO4NCSI.pdf

Page 17/17 